\title{
A Narrative Review of Ethnic Minority Studies for Faith-Based Health Promotion Interventions with special reference to the contemporary Christian nurse
}

\section{Authorship}

Lisa A. Blankinship PhD ${ }^{1}$; William A. Rouse RN, BSN ${ }^{2}$; Joshua Bernstein PhD, CHES ${ }^{3}$; Joanna Kruk PhD ${ }^{4}$; Basil H. Aboul-Enein EdD, FACN, FRSPH ${ }^{5}$

\author{
Affiliation \\ ${ }^{1}$ Department of Biology \\ University of North Alabama \\ 1 Harrison Plaza \\ Florence, AL, USA \\ Email: lblankinship@una.edu \\ ${ }^{2}$ Anderson College of Nursing and Health Professions \\ University of North Alabama \\ Florence, AL 35632 \\ E-mail:warouse@una.edu \\ ${ }^{3}$ A.T. Still University of Health Sciences \\ College of Graduate Health Studies \\ 800 W. Jefferson St. \\ Kirksville, MO 63501 USA \\ E-mail: jbernstein@atsu.edu \\ ${ }^{4}$ University of Szczecin \\ Faculty of Physical Culture and Health Promotion \\ Al. Piastów 40b/6 \\ 71-065 Szczecin \\ Poland \\ E-Mail: joanna.kruk@univ.szczecin.pl \\ ${ }^{5}$ London School of Hygiene \& Tropical Medicine \\ Faculty of Public Health and Policy \\ 15-17 Tavistock Place \\ London \\ WC1H 9SH \\ United Kingdom \\ E-mail: Basil.Aboul-Enein@1shtm.ac.uk
}


Address correspondence and reprint requests to:

Basil H. Aboul-Enein

London School of Hygiene \& Tropical Medicine

Faculty of Public Health and Policy

15-17 Tavistock Place

London

WC1H 9SH

United Kingdom

E-mail: Basil.Aboul-Enein@1shtm.ac.uk 


\title{
Keywords
}

Faith-based health education; African American; Christian nursing

\section{A Narrative Review of Ethnic Minority Studies for Faith-Based Health Promotion Interventions with special reference to the contemporary Christian nurse}

\begin{abstract}
Heart disease, Diabetes Mellitus (DM) type 2, and obesity are three of the most prevalent diseases in the United States. Some obesity-related comorbidities are disproportionately higher within African American and Hispanic communities. While governmental and local health programs offer educational opportunities encouraging long-term health behavior changes, the most accessible programs have been through faith-based communities. This narrative review investigates the outcomes of faith-based wellness programs on Latino and African American populations with respect to general health and wellness, obesity management, DM type 2, and hypertension. Perceived authority of faith community nurses, faith leaders, and accountability and encouragement provided by faith communities are critical. Long-term behavior change is positively affected by elements faith-based organizations can provide: Cultural appropriateness, community support, and self-efficacy.
\end{abstract}




\section{Introduction}

\section{Why Faith Based Health Programs?}

According to data released from the Centers for Disease Control and Prevention (CDC), adult obesity heart disease, and Type 2 diabetes mellitus (DM type 2) are disproportionately high among African American and Hispanic communities (CDC., 2019; Ogden et al., 2017). These conditions are often comorbid and all are associated with a westernized diet high in saturated fats, simple sugars, salt and paired with decreased physical activity (CDC., 2017a, 2017b, 2018; Ogden et al., 2017). Education and income level significantly and adversely affect incidence of disease while government programs have had little immediate or sustained effect on decreasing disease prevalence rates within African American and Hispanic communities.

A 2011-14 National Health and Nutrition Examination Survey suggested obesity rates varied by household income, race, and gender within the United States. Ogden et al. (2017) reports women from middle (42.9\%) and low (45.2\%) income groups are more likely to struggle with obesity for all ethnic groups outside of African Americans who were equally at risk for obesity regardless of their income level. Additionally, Hales, Carroll, Fryar, and Ogden (2017) found obesity rates among African American women (54.8\%) and Hispanic women (50.6\%) were significantly higher than Caucasian women (38.0\%). New guidelines for the Healthy People 2020 program sets a goal of $30.5 \%$ obesity among all U.S. adults (Hales et al., 2017). Education has a key role in reducing risk of obesity regardless of ethnicity (Ogden et al., 2017) and decreases the likelihood of developing DM type 2. According to 2013-15 data provided by the CDC, persons having less than a complete high school education were twice as likely to develop DM type 2 (CDC., 2018). Education may also be used as a socioeconomic indicator; communities with lower education rates are typically lower income (CDC., 2017c). According 
to the National Diabetes Statistics Report for $2017,30.3$ million or $9.4 \%$ of the U.S. population currently have DM type 2 with 7.2 million or $23.8 \%$ of cases being undiagnosed; Native Americans had the highest rate of DM type 2 (15.1\%), non-Hispanic African Americans the second highest rate $(12.7 \%)$, and Hispanics had the third highest rate (12.1\%). Non-Hispanic Caucasians (7.4\%) and Asians (8.0\%) had low rates of diabetes compared to other racial and ethnic groups (CDC., 2017c).

Each year, approximately $25 \%$ of deaths in the United States can be attributed to heart disease with over half of Americans possessing one or more risk factors for the development of heart disease including alcohol use, diabetes, physical inactivity, obesity/overweight, or poor diet. Heart disease is a leading cause of death for African Americans, Caucasians, and Hispanics and is the second leading cause of death for Asians, Native Americans, and Pacific Islanders (CDC, 2018a). According to CDC statistics, African Americans and Caucasians are equally likely to die of heart disease (CDC, 2019). As with DM type 2 and obesity, education and socioeconomics contribute to the likelihood of developing cardiovascular disease (Degano et al., 2017).

One method for bridging the gap in known methods to improve health and helping to teach and motivate people to make necessary lifestyle changes is through the use of faith-based wellness programs. While not all congregations are able to provide wellness programs or even to staff a full-time faith community nurse to assist parishioners, many faith congregations are able to partner with local resources to offer health training and short term (e.g., 4 - 16 week) programs with the established goal of helping faith community members to improve their health through diet and exercise changes, accountability, and fellowship (Baruth \& Wilcox, 2013; Cooper, King, \& Sarpong, 2015; Wilcox et al., 2018). Because religious texts are viewed as being 
authoritative and religious organizations are often able to reach more people across

socioeconomic barriers, faith community-based organizations are often able to make impacts that governmental or medical entities are not (Harmon et al., 2014; Schwingel \& Gálvez, 2015). This narrative paper investigates the outcomes of faith-based wellness programs on Latino and African American populations with respect to general health and wellness (Baruth \& Wilcox, 2013; Hardison-Moody et al., 2011; Harmon et al., 2014; Schwingel \& Gálvez, 2015; Wilcox et al., 2018), obesity management (Cooper et al., 2015; Gonzalez, Villanueva, \& N Grills, 2012; He et al., 2013), DM type 2 (Gutierrez et al., 2014; Morales-Alemán, Moore, \& Scarinci, 2018), and heart disease, specifically hypertension (Dodani, Beayler, Lewis, \& Sowders, 2014) and the role of the contemporary Christian faith-based nurse.

\section{Why Faith Based Communities?}

While governmental agencies and healthcare providers often fail at helping patients achieve long-term lifestyle changes, faith-based communities or religious organizations have had greater success (Campbell et al., 2007; Cooper et al., 2015; Harmon et al., 2014; Schwingel \& Gálvez, 2015). This article looks primarily at the success of Christian-based organizations and religious communities. The role of the faith community nurse has proven essential in providing sound guidance for health-based program development, deployment, and faith community member advocacy with respect to facing health challenges. Faith community nurses are found within Christian faith communities (also known as "parish nurses"), Jewish faith communities, and Islamic faith communities (Bard, 2006; Chatters, Levin, \& Ellison, 1998). This is most likely due to accessibility of resources, a sense of community, and the perceived authority of religious 
leaders within the faith community all within a culturally sensitive environment (Campbell et al., 2007; Gotwals, 2018; Morales-Alemán et al., 2018).

In addition to teaching resources and support offered by faith community nurses, many faith communities offer a food pantry, produce exchange program, or a community garden for members in need. These programs offer faith community members fresh produce during growing seasons and access to food year-round that does not require government programs that may impose guidelines or restrictions on types of foods allowed per person. Governmental programs may omit culturally appropriate foods from their permissible food lists (Odoms-Young et al., 2014; St Fleur \& Petrova, 2014). Faith community sponsored gardens allow members to grow or help grow fresh produce for individual use. Participation can develop a sense of community by working on a group project, provide exercise for members, and increase accountability within the group.

While church leadership is perceived as being authoritative and their support does help promote positive health practices with the faith community, it is often the role of a faith community nurse that has the greatest effect on individual faith community members. The faith community nurse plays a key role in both educating and fostering a community approach to healthcare that is often not found outside of faith community settings. Faith community nurses have the ability to reach parishioners across age and economic barriers, develop programs specific to the needs of their faith community, and ensure regular contact with faith community participants (Gotwals, 2018; Gwilt, 1987). Flynn (2001) recognized the impact that a faith community nurse has within their faith community as a unique role that emphasizes the relatedness between faith and health and promotes positive health practices within the faith community. A model was proposed, based in biblical scripture, to help Christians achieve positive health benefits by recognizing their value 
before God, caring for others, reducing anxiety through faith in God, and maintaining balance and moderation in life (See Table 1) (Flynn, 2001).

Anderson (2016) successfully integrated public health messages into a faith-based stroke awareness program for African American females to demonstrate the importance of cultural relevance. The faith community nurse plays a key role within the faith community by teaching and empowering community members to regain and maintain healthy practices.

Jewish and Christian health programs have their origins in the Levitical priesthood (Deut. 23:14) where priest were involved in setting guidelines for diet, consumption of clean water, waste and sewage disposal, control of infectious disease, public cleanliness and nuisance abatement, and health education for the religious community (Gwilt, 1987). While public sanitation and nuisance abatements are now covered by local government, it is still the role of the faith community nurse to promote health education, healthy living, and healthy diet. Since the 2000s, several studies have investigated the success of faith community related studies and the special niche that faith community health programs fulfill within the boarder community. Church related health programs have focused on general health and wellbeing (Baruth \& Wilcox, 2013; Hardison-Moody et al., 2011; Harmon et al., 2014; Schwingel \& Gálvez, 2015; Wilcox et al., 2018), obesity management (Cooper et al., 2015; Gonzalez et al., 2012; He et al., 2013), DM type 2 management and education (Gutierrez et al., 2014; Morales-Alemán et al., 2018), and hypertension (Dodani et al., 2014).

\section{Review of the faith-based studies}

1) General Health and Wellbeing Studies 
Perhaps the single most promoted topic within faith-based organizations is a healthy lifestyle one that includes being right with God, a good work ethic, reasonable rest (e.g., on the Sabbath), good interpersonal relationships, and good health. Faith-based programs that promote health include nutrition education often with an emphasis on increased consumption of fruit and vegetables, increased physical activity, and support groups to help increase accountability in learning and living out health-promoting lifestyle changes. While larger congregations tend to have health ministers and highly promoted programs, several studies from the primary literature reflect small initiatives or initiatives across several churches. Faith-based organizations that serve African American, Latino, or medically underserved congregants tend to have the greatest effect (Baruth \& Wilcox, 2013; Schwingel \& Gálvez, 2015; Wilcox et al., 2018).

Research in South Carolina investigated the impact of a Faith, Activity, and Nutrition (FAN) program among African American churches (Baruth \& Wilcox, 2013) and a medically underserved community (Wilcox et al., 2018). The 15-month FAN programs provided faith community members with education on nutrition and physical activity. All activity was selfreported by program participants and focused on four health behavior changes: Increased fruit and vegetable intake, decreased fat intake, increased fiber intake, and increase in physical activity. Among the African American participants, the most common behavior change was a decrease in fat and an increase in fiber intake; however, $31 \%$ of study participants positively changed at least one behavior, $31 \%$ of participants positively changed at least two behaviors, $13 \%$ of participants positively changed at least three behaviors, and $5 \%$ of study participants were able to achieve a change in all four health behaviors (Baruth \& Wilcox, 2013). These changes reflect small but successful implementation of behavioral modification that will provide health benefits to study participants. Wilcox et al. (2018) report in a medically underserved 
community, the church can provide a positive source for promoting and organizing physical activity and healthy eating messages, especially if such programs are supported by church leadership (Wilcox et al., 2018).

A similar study in North Carolina, the Faithful Families Eating Smart and Moving More (Faithful Families) program, demonstrates the effect local churches have on low-income congregants. Participants included 941 members across 41 faith-based organizations of which 8.1\% lacked any high school education; the majority of members were African Americans (70.5\%) compared with Caucasians (25\%) and Hispanics (1.4\%). Most members (71.6\%) were overweight or obese and impoverished (62.6\% by national 2011 standards) with members suffering from heart disease $(7.1 \%)$, diabetes (37.1\%), high cholesterol $(24.3 \%)$, and high blood pressure $(37.1 \%)$. Faithful Families provided multi-level partnerships between the various faithbased organizations, North Carolina Cooperative Extension Service, and the North Carolina Department of Public Health that developed a series of education sessions on nutrition, food resource management, food safety, and physical activity. Results from the Faithful Families program reflected an increase in physical activity (32\%), fruit (42\%) and vegetable (49\%) consumption, and nutrition practices such as food safety, meal planning, and checking food labels (83\%) (Hardison-Moody et al., 2011). While governmental programs are important and provide essential funds and resources, the community church is a key stakeholder in providing resources to the people and promoting healthy lifestyle changes through accountability and encouragement.

The Dash of Faith pilot program (Harmon et al., 2014) investigated the potential benefits of a nutrition education program within two African American churches - one church serving as control group and one as an intervention group. Program goals were to increase fruit and 
vegetable consumption among participants. The 8-month study included 12 weekly classes for participants in both churches that provided nutrition education, meal prep workshops with provided recipes, guest speakers for selected topics, and participant discussions regarding barriers to meeting participant goals. While the control group received lectures and workshops provided by the study leaders, the intervention group used local leaders within the African American community who had expertise in the topics covered by the Dash of Faith program and included monthly potlucks for participants to practice their newly acquired skills in food prep and food selection. The intervention group included ten participants while the control group included 13; both groups represented similar churches based on health ministry programs, facilities, and congregant size. The majority of participants in both cohorts were women many of which had only a high school diploma or less education. The outcomes showed the intervention group did have a higher fruit and vegetable intake when compared to the control group during the second month of the study yet did not retain this lead when compared with the control group at months six and eight. There was no significant difference between the intervention and control groups with respect to decreased fat consumption (Harmon et al., 2014). These data suggest that short term (e.g. two or four month) programs would have the greatest chance of success rather than long-term (e.g., eight month) programs. This could in part be due to participant bias (Harmon et al., 2014), a decrease in participant motivation, or even life changes that derail healthy eating habits of participants.

Due to the faith-based organizations being at the core of Hispanic life (Schwingel \& Gálvez, 2015; Villatoro, Dixon, \& Mays, 2016; Villatoro, Morales, \& Mays, 2014), faith related health programs can have an unique effect within the Latino community. Many Hispanics look to their faith-based community as a trusted authority figure thus the local faith-based organizations can 
strongly influence behavior patterns among its parishioners (Schwingel \& Gálvez, 2015).

Abuelas en Acción (AEA) is a Latino community-based health program linked closely with the Catholic Church such that health education sessions are tied to Bible readings, church hymns, and Catholic teachings. Participants are provided health education in a culturally relevant way that promoted both completion of the AEA program and long-term changes to develop a healthy lifestyle (Schwingel \& Gálvez, 2015).

\section{2) Obesity Management}

The highest rates of obesity among Americans occurs within the African American population, specifically among African American women (Timmons, 2014). While not true for all African Americans, those that practice religion tend to be highly involved within their faith communities that act as both a social and religious community cornerstone (Young, Patterson, Wolff, Greer, \& Wynne, 2014). The local faith-based community meets not only the needs of its congregants but also those of the local community by addressing social welfare, educational, health, and social justice needs; therefore, the faith-based community plays a key role in promoting good health behaviors (Young et al., 2014). Because obesity is linked to higher risks for heart disease, high blood pressure, stroke, and diabetes (Cooper et al., 2015), faith community-based weight management programs have the potential for high impact in behavioral changes for both community and faith community members.

Project HEAL (Healthy Eating, Active Lifestyles) and Project TEACH (Transforming, Empowering, and Affecting Congregation Health) represent two faith-based community weight management programs that promote culturally significant health education (Cooper et al., 2015). Project HEAL was a 10-week nutrition and physical activity course that encouraged peer 
interaction and group sharing as a way of increasing accountability and long-term change among participants. By the end of the program, participants experienced an average 1.4\% decrease in body fat compared to a $1 \%$ body fat increase in a control group (Cooper et al., 2015). Likewise, Project TEACH was a 12-week study that also focused on nutrition and physical activity education. While TEACH utilized a series of education sessions to highlight skills such as reading and understanding food labels, food prep demonstrations, and the mental and physical health influences on food consumption; it also provided sessions on physical activity and linking good eating habits and physical activity to faith (1 Cor 6:9). Project TEACH directly utilized faith community nurses to promote health, holistic wellness, and a safe environment through a variety of instructional sessions, meal prep demonstrations, and physical activity classes such as dance, aerobics, plyometric training, relay games, and yoga. After completing Project TEACH, participants showed decreases in circumference measurements (arm, neck, hips, thigh, and waist), weight, and BMI. While participants commented on TEACH's enjoyment, the biggest take away was positive lifestyle changes had been made (Cooper et al., 2015). Perhaps the most important aspect of the HEAL and TEACH projects were that they produced long-term changes within participant lives and built and/or strengthened relationships among faith community participants that provided additional social interactions and accountability after the program was concluded.

Studies that focus strictly on obesity within the adult Hispanic population are rather limited and mostly center on community-based efforts. Gonzalez et al. (2012) and He et al. (2013) describe the need for education related programs and the development of safe recreation areas especially for children. Both recommend a dual approach - better food choices and increased activity for Hispanics (Gonzalez et al., 2012; He et al., 2013). While the role of the local faith community in 
meeting the needs of the Hispanic community is the same as those needs of the African American community, there seems to be an approximate one decade lag in church-sponsored programs for Latinos.

\section{3) DM Type 2 Management and Education}

DM type 2 is prevalent among all American communities though persons with lower education and members of the African American or Hispanic communities tend to have higher rates. The prevalence of diabetes within the African American community alone has more than doubled since 2000 (Newlin, Dyess, Allard, Chase, \& Melkus, 2012). While diabetic education programs and federal incentives for offering such programs exist, there are often problems with both provider and patient in receiving the information and support necessary to make such programs viable. Providers often encounter problems with physical resources (e.g., time, lack of support staff, and access to materials that meet current diabetic education standards) and cultural resources (e.g., training on how to provide education in a culturally sensitive manner). Patients often mistrust healthcare providers and healthcare systems, especially when there is no established relationship with providers, and financial barriers (Newlin et al., 2012). Due to patient distrust, the CDC and the National Institutes of Health (NIH) recommend and support local healthcare providers, community health program leaders, and federal and state program coordinators partner with faith-based community leaders to promote education in a culturally sensitive manner (Newlin et al., 2012).

Two programs of interest include Healthy Congregations Healthy Communities (HCHC) Program sourced in Alabama (Morales-Alemán et al., 2018) and Fine, Fit, and Fabulous (FFF) which is set in New York City neighborhoods (Gutierrez et al., 2014). Both programs use 
connections with faith-based communities to provide culturally sensitive diabetic education, fitness activities, and links to scripture for the African American and Latino populations they serve (Gutierrez et al., 2014; Morales-Alemán et al., 2018). The FFF program provided education and resources for 183 participants in 15 churches in the Bronx and Harlem, New York, who, at the end of the month long program, reported they were better able to judge portion size, read and understand food labels, increase activity and exercise, and begin eating fruit daily (Gutierrez et al., 2014). The HCHC program offered a unique approach to education by training 35 faith community leaders within African American churches located in Alabama. Pastors were asked to nominate parishioners who would agree to attend training sessions, provide training for one year, were interested in healthcare, were effective communicators, and were respected members of their local congregations (Morales-Alemán et al., 2018). While members other than faith community nurses could be nominated, the faith community nurse was an ideal candidate for such training and education program of their local faith community members. Community health leaders would receive training in health care access, diabetes education, the Wellness Model which includes both physical and spiritual wellness, nutrition, stress management, and physical activity. Training not only increased community health leaders' knowledge but also increased confidence in their ability to carry out wellness related education sessions within their faith-based community (Morales-Alemán et al., 2018).

\section{4) Heart Disease}

Hypertension and related heart disease is a leading cause of death within the African American, Caucasian, and Hispanic communities (CDC., 2017a, 2017b). As with any health behavior modification or education program, the local faith community offers an influential platform for 
reaching people in a trusted and culturally sensitive manner. This is most evident within African American communities due to the local faith community's historical role within African American culture and society (Dodani et al., 2014). Dodani et al. (2014) describes the effects of HEALS (Healthy Eating and Living Spiritually) program, a faith-based community program that targets cardiovascular disease within African American churches of Jacksonville, FL though the use of faith community nurses and lay health advisors. Because the program partners with local faith-based communities, it benefits from faith community support networks, has the ability to reach members who would not otherwise accept or seek help, allows faith community members to care for one another, and provides care in a cost effective manner (Dodani et al., 2014). HEALS is a 12-week program that provides participant education on nutrition, meal prep, applying health eating skills to eating out, motivation, and training on how to deal with setbacks and negativity. Dodani et al. (2014) note programs that provide training for lay educators or faith community nurses must be further evaluated for their long-term ability to effect and maintain behavior change within their local faith communities.

\section{Conclusions}

Contemporary literature continues to support the association between religious involvement and health lifestyle behaviors (Chatters, 2000; Gotwals, 2018; Kyryliuk, Baruth, \& Wilcox, 2015; Lancaster, Carter-Edwards, Grilo, Shen, \& Schoenthaler, 2014; Levin, 2014; Sattin et al., 2016; Timmons, 2014; Yeary et al., 2015; Young et al., 2014). Perhaps the most significant barrier to any health education program is the ability to produce long-term behavior change for program participants. While education programs may motivate short-term change, lifestyle behavior change is dependent upon several factors such as cultural appropriateness, long-term 
commitment to achieve and maintain health goals, resources to achieve and sustain short and long-term goals, interpersonal and community support, and self-efficacy. Governmental programs may provide participants with resources and education, but they often lack the longterm relationship commitments that faith-based organizations provide; in addition, some people have difficulty accessing medical health programs and may lack trust in governmental or health care provider sponsored programs. Faith-based organizations, however, are seen as an authority figure within Hispanic communities and a cornerstone of African American communities (Harmon et al., 2014; Schwingel \& Gálvez, 2015). However, the local faith community historically has not qualified for government aid to develop and maintain faith-based education programs (Levin, 2014), thus faith communities that serve and support low income communities may not have the resources necessary to meet the health needs of their congregants. With the CDC's and NIH's backing, more university and government sponsored programs are reaching out to faith-based organizations to better serve people in need (Morales-Alemán et al., 2018; Newlin et al., 2012). Additionally, growing literature continues to support the role and value of the faith community nurse as key in implementing health education programs, providing resources through the local church, and building and encouraging positive, motivating relationships between program participants, nurse education, patient care, and reflective practice (Fawcett \& Noble, 2004; Gotwals, 2018; McKnight, 2017; Murphy \& Walker, 2013; Pfeiffer, 2018; Pfeiffer, Gober, \& Taylor, 2014; Rieg, Newbanks, \& Sprunger, 2018; Simon, Hodges, \& Schoonover-Shoffner, 2020; Taylor, Park, \& Pfeiffer, 2014). Campbell et al. (2007) suggest health interventions that incorporate a spiritual element have been successfully used within the African American community as these programs play a key role in positive behavioral change. Young et al. (2014) adds that religious based organizations have the unique ability to address 
public health needs in a diverse population, often reaching into communities where other programs could not. This is a research gap worthy of further exploration. Regardless of the method, faith-based programs provide access that governmental programs lack and are thereby able to affect long-term behavior changes and provide accountability thought congregant relationships. 


\section{References}

Anderson, S. H. (2016). An Investigation of Stroke Awareness among African American Women in Faith Based Organizations: A Mixed Methods Intervention Study. (EdD), A.T. Still University of Health Sciences. Retrieved from https://search.proquest.com/openview/211b328895bdc651a21c9c46060c8b3d/1?pqorigsite $=$ gscholar $\& \mathrm{cbl}=18750 \&$ diss $=\mathrm{y} \quad$ (ProQuest Number 10141477)

Bard, J. A. (2006). Faith Community Nurses and the Prevention and Management of Addiction Problems. Journal of Addictions Nursing, 17(2), 115-120. doi:10.1080/10884600600668302

Baruth, M., \& Wilcox, S. (2013). Multiple behavior change among church members taking part in the faith, activity, and nutrition program. Journal of Nutrition Education and Behavior, 45(5), 428-434. doi:10.1016/j.jneb.2013.03.002

Campbell, M. K., Hudson, M. A., Resnicow, K., Blakeney, N., Paxton, A., \& Baskin, M. (2007). Church-based health promotion interventions: evidence and lessons learned. Annual review of public health, 28, 213-234. doi:10.1146/annurev.publhealth.28.021406.144016

CDC. (2017a). Heart Disease Fact Sheet. Retrieved from https://www.cdc.gov/dhdsp/data_statistics/fact_sheets/fs_heart_disease.htm

CDC. (2017b). Heart Disease Facts. Retrieved from https://www.cdc.gov/heartdisease/facts.htm

CDC. (2017c). National Diabetes Statistic Report, 2017. Retrieved from https://www.cdc.gov/features/diabetes-statistic-report/index.html

CDC. (2018). Incidence of Diagnosed Diabetes. Retrieved from https://www.cdc.gov/diabetes/data/statistics-report/incidence-diabetes.html

CDC. (2019). Health, United States Spotlight - Racial and Ethnic Disparities in Heart Disease. Retrieved from https://www.cdc.gov/nchs/hus/spotlight/2019-heart-diseasedisparities.htm

Chatters, L. M. (2000). Religion and health: public health research and practice. Annual review of public health, 21, 335-367. doi:10.1146/annurev.publhealth.21.1.335

Chatters, L. M., Levin, J. S., \& Ellison, C. G. (1998). Public health and health education in faith communities. Health education \& behavior, 25(6), 689-699. doi:10.1177/109019819802500602

Cooper, K. C., King, M. A., \& Sarpong, D. F. (2015). Tipping the scales on obesity: churchbased health promotion for African American women. Journal of Christian Nursing, 32(1), 41-45.

Degano, I. R., Marrugat, J., Grau, M., Salvador-Gonzalez, B., Ramos, R., Zamora, A., . . . Elosua, R. (2017). The association between education and cardiovascular disease incidence is mediated by hypertension, diabetes, and body mass index. Scientific reports, 7(1), 12370. doi:10.1038/s41598-017-10775-3

Dodani, S., Beayler, I., Lewis, J., \& Sowders, L. A. (2014). HEALS Hypertension Control Program: Training Church Members as Program Leaders. The Open Cardiovascular Medicine Journal, 8, 121-127. doi:10.2174/1874192401408010121

Fawcett, T. N., \& Noble, A. (2004). The challenge of spiritual care in a multi-faith society experienced as a Christian nurse. Journal of Clinical Nursing, 13(2), 136-142. doi:10.1046/j.1365-2702.2003.00870.x

Flynn, L. (2001). A Christian model of health promotion. Journal of Christian Nursing, 18(1), 31-33. 
Gonzalez, E., Villanueva, S., \& N Grills, C. (2012). Communities Creating Healthy Environments to Combat Obesity: Preliminary Evaluation Findings From Two Case Studies. Californian Journal of Health Promotion, 10, 88-98. doi:10.32398/cjhp.v10iSILatino. 1486

Gotwals, B. (2018). Self-Efficacy and Nutrition Education: A Study of the Effect of an Intervention with Faith Community Nurses. Journal of Religion and Health, 57(1), 333348. doi:10.1007/s10943-017-0465-2

Gutierrez, J., Devia, C., Weiss, L., Chantarat, T., Ruddock, C., Linnell, J., . . Calman, N. (2014). Health, Community, and Spirituality: Evaluation of a Multicultural Faith-Based Diabetes Prevention Program. Diabetes Educator, 40(2), 214-222. doi:10.1177/0145721714521872

Gwilt, J. R. (1987). Public health in the Bible. Journal of the Royal Society of Health, 107(6), 247-248.

Hales, C. M., Carroll, M. D., Fryar, C. D., \& Ogden, C. L. (2017). Prevalence of obesity among adults and youth: United States, 2015-2016. Retrieved from https://www.cdc.gov/nchs/products/databriefs/db288.htm

Hardison-Moody, A., Dunn, C., Hall, D., Jones, L., Newkirk, J., \& Thomas, C. (2011). MultiLevel Partnerships Support a Comprehensive Faith-Based Health Promotion Program. Journal of Extension, 49(6), 1-5.

Harmon, B. E., Adams, S. A., Scott, D., Gladman, Y. S., Ezell, B., \& Hebert, J. R. (2014). Dash of Faith: A Faith-Based Participatory Research Pilot Study. Journal of Religion and Health, 53(3), 747-759. doi:10.1007/s10943-012-9664-Z

He, M., Wilmoth, S., Bustos, D., Jones, T., Leeds, J., \& Yin, Z. (2013). Latino church leaders' perspectives on childhood obesity prevention. American Journal of Preventive Medicine, 44(3 Suppl 3), S232-239. doi:10.1016/j.amepre.2012.11.014

Kyryliuk, R., Baruth, M., \& Wilcox, S. (2015). Predictors of Weight Loss for African-American Women in the Faith, Activity, and Nutrition (FAN) Study. Journal of Physical Activity and Health, 12(5), 659-665. doi:doi:10.1123/jpah.2013-0220

Lancaster, K. J., Carter-Edwards, L., Grilo, S., Shen, C., \& Schoenthaler, A. M. (2014). Obesity interventions in African American faith-based organizations: A systematic review. Obesity Reviews, 15, 159-176. doi:10.1111/obr.12207

Levin, J. (2014). Faith-based initiatives in health promotion: history, challenges, and current partnerships. American journal of health promotion, 28(3), 139-141. doi:10.4278/ajhp.130403-CIT-149

McKnight, H. (2017). Aligning Career with Faith: Reflective Practice for Christian Nurse Educators. Journal of Christian Nursing, 34(2), E23-E25. doi:10.1097/CNJ.0000000000000376

Morales-Alemán, M. M., Moore, A., \& Scarinci, I. C. (2018). Development of a Participatory Capacity-Building Program for Congregational Health Leaders in African American Churches in the US South. Ethnicity \& disease, 28(1), 11-18. doi:10.18865/ed.28.1.11

Murphy, L. S., \& Walker, M. S. (2013). Spirit-guided care: Christian nursing for the whole person. Journal of Christian Nursing, 30(3), 144-152; quiz 153-144. doi:10.1097/cnj.0b013e318294c289

Newlin, K., Dyess, S. M., Allard, E., Chase, S., \& Melkus, G. D. (2012). A methodological review of faith-based health promotion literature: advancing the science to expand 
delivery of diabetes education to Black Americans. Journal of Religion and Health, 51(4), 1075-1097. doi:10.1007/s10943-011-9481-9

Odoms-Young, A. M., Kong, A., Schiffer, L. A., Porter, S. J., Blumstein, L., Bess, S., . . . Fitzgibbon, M. L. (2014). Evaluating the initial impact of the revised Special Supplemental Nutrition Program for Women, Infants, and Children (WIC) food packages on dietary intake and home food availability in African-American and Hispanic families. Public Health Nutrition, 17(1), 83-93. doi:10.1017/s1368980013000761

Ogden, C. L., Fakhouri, T. H., Carroll, M. D., Hales, C. M., Fryar, C. D., Li, X., \& Freedman, D. S. (2017). Prevalence of Obesity Among Adults, by Household Income and Education United States, 2011-2014. MMWR. Morbidity and mortality weekly report, 66(50), 13691373. doi:10.15585/mmwr.mm6650a1

Pfeiffer, J. (2018). Strategies christian nurses use to create a healing environment. Religions, 9(11). doi:10.3390/re19110352

Pfeiffer, J. B., Gober, C., \& Taylor, E. J. (2014). How christian nurses converse with patients about spirituality. Journal of Clinical Nursing, 23(19-20), 2886-2895. doi:10.1111/jocn.12596

Rieg, L. S., Newbanks, R. S., \& Sprunger, R. (2018). Caring from a Christian Worldview: Exploring Nurses' Source of Caring, Faith Practices, and View of Nursing. Journal of Christian Nursing, 35(3), 168-173. doi:10.1097/CNJ.0000000000000474

Sattin, R. W., Williams, L. B., Dias, J., Garvin, J. T., Marion, L., Joshua, T. V., . . Venkat Narayan, K. M. (2016). Community Trial of a Faith-Based Lifestyle Intervention to Prevent Diabetes Among African-Americans. Journal of Community Health, 41(1), 8796. doi:10.1007/s10900-015-0071-8

Schwingel, A., \& Gálvez, P. (2015). Divine Interventions: Faith-Based Approaches to Health Promotion Programs for Latinos. Journal of Religion and Health. doi:10.1007/s10943015-0156-9

Simon, E. B., Hodges, R., \& Schoonover-Shoffner, K. (2020). Experiencing God in Nursing. Journal of Christian Nursing, 37(2), 94-99. doi:10.1097/CNJ.0000000000000637

St Fleur, R., \& Petrova, A. (2014). Knowledge and perception of breastfeeding practices in Hispanic mothers in association with their preferred language for communication. Breastfeeding medicine, 9(5), 261-265. doi:10.1089/bfm.2013.0145

Taylor, E. J., Park, C. G., \& Pfeiffer, J. B. (2014). Nurse religiosity and spiritual care. Journal of Advanced Nursing, 70(11), 2612-2621. doi:10.1111/jan.12446

Timmons, S. M. (2014). Review and Evaluation of Faith-Based Weight Management Interventions That Target African American Women. Journal of Religion and Health, 54(2), 798-809. doi:10.1007/s10943-014-9912-5

Villatoro, A. P., Dixon, E., \& Mays, V. M. (2016). Faith-based organizations and the Affordable Care Act: Reducing Latino mental health care disparities. Psychological services, 13(1), 92-104. doi:10.1037/a0038515

Villatoro, A. P., Morales, E. S., \& Mays, V. M. (2014). Family culture in mental health helpseeking and utilization in a nationally representative sample of Latinos in the United States: The NLAAS. The American journal of orthopsychiatry, 84(4), 353-363. doi: 10.1037/h0099844

Wilcox, S., Saunders, R. P., Kaczynski, A. T., Forthofer, M., Sharpe, P. A., Goodwin, C., . . . Hutto, B. (2018). Faith, Activity, and Nutrition Randomized Dissemination and 
Implementation Study: Countywide Adoption, Reach, and Effectiveness. American Journal of Preventive Medicine, 54(6), 776-785. doi:10.1016/j.amepre.2018.02.018

Yeary, K. H. C. K., Cornell, C. E., Prewitt, E., Bursac, Z., Tilford, J. M., Turner, J., . . Harris, K. (2015). The WORD (Wholeness, Oneness, Righteousness, Deliverance): Design of a randomized controlled trial testing the effectiveness of an evidence-based weight loss and maintenance intervention translated for a faith-based, rural, African American population using a community-based participatory approach. Contemporary Clinical Trials, 40, 6373. doi:10.1016/j.cct.2014.11.009

Young, S., Patterson, L., Wolff, M., Greer, Y., \& Wynne, N. (2014). Empowerment, Leadership, and Sustainability in a Faith-Based Partnership to Improve Health. Journal of Religion and Health. doi:10.1007/s10943-014-9911-6 
Table 1. Model of Health Promoting Behaviors with Key Biblical References

\begin{tabular}{|c|c|}
\hline Behavior-Oriented Themes & Scripture References \\
\hline Recognize value before God & $\begin{array}{l}\text { Ps. 91:11; Mt 10:29-31; Lk 12:6-7; Rom 5:8; } \\
\text { Rom 8:38-39; Eph 3:18-19; } 1 \text { Jn 4:10 }\end{array}$ \\
\hline Caring for others & $\begin{array}{l}\text { Mt 19:19; Mt 22:39; Mk 12:33; Lk 6:27; Lk } \\
\text { 10: 29-37; Jn 13:34-35; Jn 15:12; Rom 13:8- } \\
\text { 9; Gal 5:13-14; Eph 4:2; Eph 4:32; } 1 \text { Thess } \\
\text { 4:9; I Thess 4:14; Heb 13:1-3; Jas 2:8; } 1 \text { Pet } \\
\text { 1:22; } 1 \text { Jn } 3: 11 ; 1 \text { Jn } 3: 18 ; 1 \text { Jn 4:7 }\end{array}$ \\
\hline Reducing anxiety through faith in God & Ps 37:8-9; Prov 20:24; Mt 6:25-34; Phil 4:6 \\
\hline Maintaining balance and moderation in life & $\begin{array}{l}\text { Ex 16:23, Ex 20:8, Ex34:21, Ex. 35:2; Eccles } \\
3: 1-8,12-13 ; \text { Mk 2:27 }\end{array}$ \\
\hline
\end{tabular}

Note: Flynn (2001) developed the themes to promote healthy 'Christian' living based on four recurrent themes mentioned in the Bible. 